\title{
Implementing the process oriented guided-inquiry learning (POGIL) pedagogy of group scenario exercises in Fundamentals and Medical Surgical II nursing courses
}

\author{
Susan Zori ${ }^{1,2}$, Maureen Carroll Roller*1,3, Erik Lyons ${ }^{1,4}$ \\ ${ }^{1}$ College of Nursing \& Public Health, Adelphi University, Garden City, NY, United States \\ ${ }^{2}$ Long Island Jewish Medical Center (Northwell Health), New Hyde Park, NY, United States \\ ${ }^{3}$ St Francis Hospital (Catholic Health System), Roslyn, NY, United States \\ ${ }^{4}$ South Nassau Communities Hospital, Oceanside, NY, United States
}

Received: April 25, 2018

DOI: $10.5430 /$ jnep.v8n12p1
Accepted: June 18, 2018

Online Published: June 26, 2018

\begin{abstract}
Background and objective: Research with Process Oriented Guided Inquiry Learning (POGIL), an interactive learning pedagogy, has shown improvement in grades and student satisfaction in science and nursing courses. POGIL is an active teaching strategy which utilizes small groups of students to analyze case studies. The student teams participate in groups of four to problem solve topics based on the material taught. POGIL can be additional to lecture and didactic teaching methods to help with the synthesis and analysis of content taught. The object of this study was to compare final course and national standardized exam grades between POGIL and comparison groups in both Fundamentals and Medical-Surgical II nursing courses.

Methods: A quantitative, comparative design was used.

Results: The Fundamentals POGIL group had significantly higher scores on a standardized national exam $(p=.001)$ than a comparison group; no significant difference in final course grades was found. The Medical-Surgical Nursing II POGIL and comparison groups had no significant differences in standardized national exam or final course grades. Students in POGIL groups were given a satisfaction survey and indicated the experience was helpful to improving grades and understanding course content. Conclusions: In classes that used POGIL, there were higher scores on a standardized national exam scores but not final course grades for students in the Fundamentals course. Using POGIL in Medical Surgical Nursing II courses revealed no difference in final course grades or on national standardized exam scores. The use of POGIL for beginning nursing students may be more helpful as these students are in the process of determining which learning strategies are most helpful as they progress through the nursing curriculum. Introducing a new pedagogy to students in their last semester of the nursing program was not as helpful possibly because students have established successful strategies for learning prior to this last semester. Future research to further explore the impact of POGIL on grades and standardized tests scores in other nursing curriculum courses such as mental health or care of the emerging family is recommended. Exploring POGIL and the impact on the development of clinical thinking and clinical practice is another line of inquiry that could be explored.
\end{abstract}

Key Words: Active learning Process-Oriented Guided Inquiry Learning research (POGIL), Fundamental nursing course, Medical-Surgical nursing II course, Case studies

*Correspondence: Maureen Carroll Roller; Email: roller@adelphi.edu; Address: College of Nursing \& Public Health, Adelphi University, Garden City, NY, United States. 


\section{INTRODUCTION}

Undergraduate nursing educators are challenged to deliver a comprehensive curriculum that supports development of essential nursing skills such as teamwork, critical thinking and problem solving that lead to the delivery of quality patient care. ${ }^{[1]}$ The Process Oriented Guided Inquiry (POGIL) pedagogy used in teaching college level chemistry, math, and fundamental nursing courses has demonstrated a positive impact on students' grades, attitudes toward the course content and satisfaction with participation in POGIL. ${ }^{[2-7]}$

POGIL pedagogy is an active learning strategy that utilizes reflection, questioning, and problem-based learning. POGIL utilizes groups of four students working as a team to solve problems or analyze case studies. When using POGIL, students work in small groups and use an exploration, invention, and application model to reinforce content and then apply problem solving to the given assignment. POGIL as a pedagogy uses student centered active learning and allows for migration away from teacher-centered lectures.

The role of the professor is as facilitator, encouraging students to seek answers rather than to provide the answers. One student in each group assumes the roles of manager, leader, recorder or reflector during the exercise. ${ }^{[8]}$ The role of the manager is to complete the task on time. The leader, at the conclusion of the exercise, reports to the class the groups' findings. Maintaining the records of the group's members and activity are the roles of the recorder. Maintaining the group's learning process is the role of the reflector. ${ }^{[9]}$

Active learning strategies are described as those that challenge students to use questioning and reflection to help make connections between concepts and to bridge the educationpractice gap. ${ }^{[10,11]}$ Nursing education research has shown that strategies such as reflection, questioning, problem-based learning, reflective writing and the use of concept mapping are considered best practices to assist students to engage in active learning and hone critical thinking skills. ${ }^{[1,12-14]}$

Problem based learning (PBL) encourages learning through questioning and self-directed research that fosters the development of critical thinking and is often used in nursing education. ${ }^{[1,14]}$ PBL has similarities and differences to POGIL. Both are similar in that they are active learning strategies that place students at the center of learning. Both strategies use small groups of students who work together to complete the given assignment. These active learning strategies are thought to promote critical thinking, and engage students in deep learning. Where they differ is that PBL provides a problem based on real life before the content material is learned. It is through working on the problem and applying research methodology that the content is learned. ${ }^{[13]}$ POGIL, similarly utilizes realistic case studies, but does so after the content material is learned, to encourage the synthesis and application of the material learned. POGIL as an active learning strategy was chosen to be examined in this study because it was consistent with the methods of teaching used in the existing curriculum and seemed to fit better with the needs of the students and faculty.

Using POGIL as a pedagogy debuted in the 1990s in college chemistry courses. Use of POGIL has expanded to other science, math, pharmacology, and nursing disciplines. ${ }^{[6,8,15,16]}$ Research has been conducted in a variety of disciplines to evaluate the efficacy of POGIL in helping to achieve positive learning outcomes.

Hein $^{[17]}$ examined the use of POGIL in college level organic chemistry courses, and compared pre-course grade point average (GPA), course grades and percentile rankings on American Chemical Society (ACS) exams. Results revealed that the POGIL groups had significantly higher course grades and percentile rankings on the ACS exam. It was also noted that students who had pre-intervention lower achievement on GPAs and were in POGIL classes, achieved higher grades than their counterparts in the control group.

Chase, Pakhira and Stains ${ }^{[2]}$ examined the use of POGIL also in undergraduate organic and general chemistry courses. Control groups were classes that did not use POGIL and experimental groups used POGIL. Student outcomes for the two groups were compared on course grades, retention, attitude toward chemistry, attitude toward the learning environment and self-efficacy. Results revealed limited or no significant differences in grades, retention, or self-efficacy. However, students' attitudes toward the learning environment was more positive in the POGIL group compared to the control group.

POGIL has been studied in a variety of subjects other than chemistry. Maurer ${ }^{[18]}$ described the adaptation of POGIL into an undergraduate financial literacy course. A lecture only section of the course was compared with a hybrid section that used lecture and POGIL. There were no statistically significant differences in scores achieved in homework assignments or final grades. Moreover, student satisfaction surveys demonstrated that students preferred lecture only to the hybrid format using POGIL. Mulligan ${ }^{[15]}$ investigated the use of POGIL to teach biotransformation in a microbiology course. This study, with limited aims, found that students preferred POGIL to lecture alone but there was no analysis of impact on grades or other assessment data.

Roller ${ }^{[5]}$ reported a significant difference $(p=.032)$ in scores from a nationally- normed exam when compared in 2 classes

ISSN 1925-4040 E-ISSN 1925-4059 
of Nursing Fundamentals courses in which the experimental group participated in POGIL $(\mathrm{N}=25)$ and the control group did not $(\mathrm{N}=25)$. This study found no significant difference between the two groups in the final grades. A subsequent study by Roller and Zori ${ }^{[6]}$ used similar methodology with a larger sample size and compared final grades and scores on a nationally normed test for nursing students: a control group with students who did not experience POGIL $(\mathrm{N}=75)$ and an experimental group $(\mathrm{N}=63)$ that used POGIL. The experimental group had statistically significant higher final course grades $(p=.046)$, reported a better understanding of the course material $(p=.005)$, and had a greater satisfaction with grades $(p=.008)$ than the control group. However, there was no significant difference between the groups scores on the national standardized exam.

Soltis et al. ${ }^{[16]}$ used POGIL in a pharmacology course and found, not only did overall test scores improve but there was a decrease by $50 \%$ in the number of $\mathrm{D}$ and $\mathrm{F}$ grades in the final course, and a $25 \%$ increase in $\mathrm{B}$ grades. This finding is similar to those of Hein ${ }^{[17]}$ who also noted that students with lower GPAs at the start achieved higher grades than their counterparts in a class that did not use POGIL. It might be speculated that POGIL, as an active learning strategy, has a positive impact on improving grades for those students who have lower overall GPAs at the onset of the experience with POGIL.

In summary, results from research conducted with POGIL are conflicting. Hein, ${ }^{[17]}$ and Roller and Zori ${ }^{[6]}$ found higher course grades when POGIL was used. Hein's ${ }^{[17]}$ results also demonstrated that students had higher percentile rankings on the national ACS exam. Roller's ${ }^{[15]}$ results found higher standardized national scores for the POGIL group, while Roller and Zori ${ }^{[6]}$ did not find significantly different results on a national standardized exam. Chase, Pakhira and Stains' ${ }^{\text {[2] }}$ results found no difference in course grades in a chemistry courses when sections of the course that used POGIL were compared with sections that did not use POGIL, a similar finding to Maurer's ${ }^{[18]}$ study using POGIL in a financial literacy course.

Overall, research findings have revealed that students' selfreported mastery of the content and their satisfaction with a course that used POGIL was better when compared to classes that used lecture only. ${ }^{[2,6,15,16]}$ Limited studies have demonstrated the use of POGIL's effect on grades. A promising outcome from the use of POGIL is that those students with lower GPAs achieve higher grades. ${ }^{[16,17]}$ Based on these outcomes, further research with POGIL is warranted. In this article we report the use of POGIL and the effect on grades in Fundamentals and Medical Surgical II nursing courses.

\subsection{Framework for the study}

Social Constructivism Learning theory was developed from the work of Piaget ${ }^{[19]}$ and Vygotsky. ${ }^{[20]}$ This theory describes learning as an active process that allows the learner to construct new knowledge through experiences that build upon prior knowledge and experience. Research on inquiry learning strategies, such as POGIL has used social constructivism theory to help explain the phenomena of active, inquiry based learning. ${ }^{[2,7,8,11]}$ Social constructivism describes student and teacher roles in an active learning environment as moving from teacher owned to the student being motivated to learn independently. The teacher role is to facilitate learning by creating inquiry based activities that stimulate student problem solving that in return builds knowledge. Studies using Social Constructivism Theory as a framework have also described the further enhancement of student learning through social interaction and the assumption of different roles to enhance critical thinking, problem solving and different perspectives on the knowledge being learned. ${ }^{[21]}$ Therefore the use of social constructivism as a framework for understanding the learning that occurs through POGIL which involves, small groups of students, socially interacting and assuming different roles during the discussion and analysis of a case student are in alignment with the tenets of social constructivism learning theory.

\subsection{Study aims}

The following three goals guided the study's methods:

(1) To examine and compare the demographics, pre-study GPA, final course grades and standardized national exam scores for students enrolled in Fundamentals courses, in which one group used POGIL during class (POGIL Group) and one group (Comparison Group) used traditional teaching methodologies.

(2) To examine and compare the demographics, pre-study GPA, final course grades and (standardized national test scores of students in two groups of Medical Surgical II nursing courses in which POGIL as a pedagogy was used and a comparison group that did not use POGIL.

(3) To describe the students' satisfaction in both the Fundamentals and Medical Surgical Nursing II courses with completing case studies using POGIL.

\section{METHODS}

\subsection{Design}

This research was a quantitative, descriptive study that utilized a comparative design. 


\subsection{Setting: Sample and recruitment}

The research was conducted in a private, non-sectarian, midsized university with several campuses in a suburban and urban setting in the northeastern region of the United States. Approval from the Institutional Review Board (IRB) at the authors' university was obtained.

A convenience sample of pre-licensure, baccalaureate, nursing students was recruited over two semesters. Students enrolled in all Fundamentals theory courses during their first semester of their junior year and all Medical Surgical Nursing II courses in the final semester of their senior year were invited to volunteer for the study. The two different courses were chosen not for comparison with each other but to provide information on the use of POGIL in two different types of courses on two different levels in this Baccalaureate program. Students registered for these courses and sections by using the normal processes for registration. At the time of registration, students did not know the identity of the professors or if they would be using POGIL or not during the semester.

After receiving permission by email from the 22 professors teaching Fundamentals and Medical-Surgical Nursing II courses, during the 2 semesters of data collection, a graduate student assistant visited both POGIL and comparison classes in both courses. The graduate student assistant invited students to participate in the study using a prepared script and if they decided to participate in the study a signed informed consent was obtained. The prepared script and informed consent document was approved by the IRB. The signed informed consent obtained from students who volunteered to participate, outlined the details of study participation and requested permission to use de-identified demographic data (age, gender, ethnicity), pre-study GPA, final course grades and standardized national test scores. The consent also addressed any risks to participating in the study which were none. Students were assured their grades would in no way be influenced by whether or not they chose to participate in the study. In the final sample 153 students consented to be in the Fundamentals POGIL group, and 109 in the comparison group. The Medical Surgical Nursing II courses had 61 consenting participants in the POGIL group and 54 in the comparison group.

Professors who were willing to learn and use POGIL in the classes they were teaching were also recruited for the study. The principal investigator, who attended a national workshop on POGIL and had used the methodology for over 5 years met, with those professors who agreed to use POGIL on an individual basis and asked them if they were willing to learn and use POGIL in the classroom and participate in the study. Consent from the participating professors was volun- tary, and verbally given, no financial or other compensation was offered for agreeing to use POGIL for the purpose of the study. The principal investigator then met with those professors who agreed to use POGIL and reviewed the how to use POGIL using the case study scenarios as well as how to form the student groups, the role of the teacher as facilitator, and the students' roles in POGIL. Participating professors were also referred to a POGIL website for further information.

\subsection{Procedure and POGIL intervention}

A final sample of nine professors who taught 16 classes of Fundamentals volunteered to participate in the study: 3 using POGIL and 6 using traditional teaching methods. Five professors in six classes taught Medical Surgical Nursing II; 3 classes used POGIL and 3 classes participated in traditional teaching methods.

A packet of six case studies which addressed a variety of clinical scenarios was distributed to each professor who would be utilizing POGIL. These case studies reinforced lecture content and were specifically designed to foster critical thinking and collaboration among participants. Approximately 45 minutes of class time was allocated for each case study. Topics for the Fundamentals course groups included: safety, medication, fluids and electrolytes, skin integrity-asepsis, oxygenation and surgery. Topics for the Medical-Surgical Nursing II classes included: oncology, urology, sensorineural, burns, hematology and HIV. The professors in the POGIL groups used class time to complete the case studies at a time when they coincided with lecture topics. The actual POGIL groups for each case study were created at the discretion of the participating professor.

The comparison classes were given the same case study packet for students to complete on an individual, voluntary basis outside of the classrooms. These case studies if completed by students would be submitted to the professor for review but were not part of the final grading for the course.

The graduate student assistant revisited each class, at the end of the semester, to invite student study participants to complete a survey related to satisfaction with using POGIL. The survey focused on assessing subjects' perceptions of the impact of POGIL on mastery of course content, and their achievement of final course grade. The survey also asked the students to rate how helpful functioning in the POGIL roles of manager, leader, reflector or recorder were to performing in a team.

\section{RESULTS}

Demographic variables for participants in the Fundamentals and Medical Surgical Nursing II groups were analyzed using 
descriptive statistics. The age, pre-GPA, final course grades and standardized national exam scores were compared within groups using a paired sample $t$-test. A comparison of means between the Medical-Surgical and Fundamentals group was not analyzed because of the assumption that the learning experiences of these 2 groups of students were very different as the Fundamentals students were in their first semester of clinical nursing courses and Medical Surgical Nursing II students were in their fourth and final semester of nursing courses.

\subsection{Fundamentals class results}

\subsubsection{Fundamentals groups' demographics}

A total of 370 students were enrolled in Fundamental classes during the 2 semesters of recruitment. Of these 370 students, 262 students participated in the study with 153 students in the POGIL group and 109 students in the comparison group, 108 students did not agree to participate in the study. The gender distribution in the POGIL group was $13.5 \%$ males and $86.5 \%$ females. This was similar to the comparison group with $11.0 \%$ males and $89 \%$ females; there was no statistical significant difference in gender between the two groups using a paired sample $t$-test. The mean age for students who were in the Fundamentals POGIL group was 21.86 years and the mean age for participants in the comparison group was 21.97 years revealing no significant difference between groups. Self-reported ethnicity in the Fundamentals POGIL group was 57.4\% White; 7.8\% African American Black; 16.9\% Asian; 8.4\%; Hispanic Latino; 0\% Native American; $0 \%$ Non-Hispanic Latino and 9.1\% Other. The Fundamentals control group with $73.7 \%$ White; $1.8 \%$ African American Black; 14\% Asian; 5.3\% Hispanic Latino; 0\% Native American; 0\% Non-Hispanic Latino and 5.3\% responded "Other".

\subsubsection{Results of comparisons for fundamentals groups}

A 2 tailed, $t$-test for independent samples compared the Fundamentals POGIL group with the comparison group for pre-study GPA, national standardized mean scores and final grades and depicted in Table 1 . There was a significant difference in means scores on for the national standardized exam grades when the two were compared. POGI L group $(\mathrm{M}=75.69, \mathrm{SD}=12.228)$ compared to the control group ( $\mathrm{M}$ $=70.41, \mathrm{SD}=12.155, p=.001)$. There was no significant difference in the final course grades of the POGIL $(\mathrm{M}=$ $88.19, \mathrm{SD}=4.428)$ vs. the comparison group $(\mathrm{M}=87.34$ $\mathrm{SD}=4.403, p=.657)$. Table 1 shows there was no significant difference between the groups on the pre-course GPAs.

Table 1. Results from $t$-test for Age, Pre-research GPA, National Standardized Exam and Final Grade mean scores for POGIL and control groups in Fundamentals nursing course

\begin{tabular}{|c|c|c|c|c|c|c|c|c|}
\hline & $\mathbf{N}$ & $\begin{array}{l}\text { Age } \\
\text { (Mean) }\end{array}$ & $\begin{array}{l}\text { Pre-research } \\
\text { GPA } \\
\text { (Mean) }\end{array}$ & $\begin{array}{l}\text { Pre- } \\
\text { research } \\
\text { GPA (SD) } \\
\end{array}$ & $\begin{array}{l}\text { National } \\
\text { Standardized } \\
\text { Exam (Mean) }\end{array}$ & $\begin{array}{l}\text { National } \\
\text { Standardized } \\
\text { Exam (SD) } \\
\end{array}$ & $\begin{array}{l}\text { Final } \\
\text { Grade } \\
\text { (Mean) }\end{array}$ & $\begin{array}{l}\text { Final } \\
\text { Grade } \\
\text { (SD) } \\
\end{array}$ \\
\hline POGIL Group & 153 & 21.97 & 3.60 & .277 & 75.69 & 12.288 & 88.19 & 4.428 \\
\hline Comparison Group & 109 & 21.86 & 3.61 & .277 & 70.41 & 12.155 & 87.34 & 4.403 \\
\hline 2 tail $t$-test significance & & $p=.874^{\mathrm{NS}}$ & $p=.657^{\mathrm{NS}}$ & & $p=.001$ & & $p=.124^{\mathrm{NS}}$ & \\
\hline
\end{tabular}

Note. SD: Standard. Deviation; NS: Not Significant.

\subsubsection{Satisfaction survey results: Fundamentals course}

Students in the Fundamentals POGIL group completed a satisfaction survey with 5 items that described the degree of helpfulness POGIL was to improving course grades; understanding course content; future teamwork participation; and POGIL role that most prepared you for future teamwork. Results revealed that $75.1 \%$ of respondents found POGIL helpful or very helpful to improving course grades; $90 \%$ found POGIL helpful or very helpful to understanding course content; and $87.1 \%$ found POGIL helpful to future teamwork participation. Analysis of the responses for POGIL roles indicated that $20.5 \%$ of respondents found the manager role helpful or very helpful in future teamwork.

Students in the Fundamentals comparison group were given the opportunity to complete a two-question survey that rated Published by Sciedu Press how helpful completing the case studies were to understand the content taught and to improving grades. Due to the low rate of return this data seemed inconsequential to the study and is not reported.

\subsection{Medical-Surgical II}

\subsubsection{Medical-Surgical II demographics}

A total of 180 students were enrolled in Medical-Surgical Nursing II classes during the 2 semesters of recruitment. A total of 115 Medical-Surgical Nursing II nursing students participated in the study with 61 students in the POGIL group and 54 in the Comparison group, 65 students did not consent to be in the study. The gender distribution in the POGIL Group was $14.8 \%$ males and $85.2 \%$ females and was similar to the Comparison Group with $13 \%$ males and $87 \%$ females. Statistical analysis revealed there was no significant 
difference between groups for gender. The mean age for participants in the Medical-Surgical Nursing II POGIL Group was 21.86 years and the mean age for participants in the Comparison Group was 25.83 years which was statistically significant at the $p=.001$ level. Because of this significance, an analysis of covariance test was employed and revealed no group effect thus indicating that the significance in age did not influence the results of the final grades or national standardized exam scores.

Ethnicity in the Medical-Surgical Nursing II POGIL Group was 70.5\% White; 3.3\% African American Black; 9.8\% Asian; 1.6\% Hispanic Latino; 0\% Native American; and
$14.8 \%$ Other. The comparison group had students who were 64.2\% White; 7.5\% African American Black; 13.2\% Asian; $1.9 \%$ Hispanic Latino; $1.9 \%$ Non-Hispanic Latino, $0 \% \mathrm{Na}-$ tive American; and $11.3 \%$ Other.

\subsubsection{Results of the Medical-Surgical Nursing II course comparison}

Independent samples, 2 tailed, $t$-test was done to compare the POGIL Group with the comparison group for pre-research GPA, standardized national exam mean scores and final grades. No significant difference was found on these scores between the groups in Table 2 .

Table 2. Results from $t$-test for Age, Pre-research GPA, National Standardized Exam, and Final Grade mean scores for POGIL and control groups in Medical Surgical Nursing II course

\begin{tabular}{|c|c|c|c|c|c|c|c|c|}
\hline & $\mathbf{N}$ & $\begin{array}{l}\text { Age } \\
\text { (Mean) }\end{array}$ & $\begin{array}{l}\text { Pre-research } \\
\text { GPA } \\
\text { (Mean) }\end{array}$ & $\begin{array}{l}\text { Pre- } \\
\text { research } \\
\text { GPA (SD) }\end{array}$ & $\begin{array}{l}\text { National } \\
\text { Standardized } \\
\text { Exam (Mean) }\end{array}$ & $\begin{array}{l}\text { National } \\
\text { Standardized } \\
\text { Exam (SD) }\end{array}$ & $\begin{array}{l}\text { Final } \\
\text { Grade } \\
\text { (Mean) }\end{array}$ & $\begin{array}{l}\text { Final } \\
\text { Grade } \\
\text { (SD) }\end{array}$ \\
\hline POGIL Group & 61 & 22.9 & 3.48 & .275 & 72.00 & 10.504 & 85.31 & .639 \\
\hline Comparison Group & 54 & 25.6 & 3.46 & .266 & 72.78 & 12.726 & 87.01 & .776 \\
\hline 2 tail $t$-test significance & & $p=.001$ & $p=.756$ & & $p=.722^{\mathrm{NS}}$ & & $p=.090^{\mathrm{NS}}$ & \\
\hline
\end{tabular}

Note. SD: Standard. Deviation; NS: Not Significant.

\subsubsection{Satisfaction survey results: Medical-Surgical II course}

Students in the Medical Surgical Nursing II POGIL group completed a satisfaction survey with 5 items that described how helpful POGIL was to improving course grades; understanding course content; future teamwork participation; and POGIL role that most prepared you for future teamwork. Analysis of the results revealed that $71.7 \%$ of respondents found POGIL helpful or very helpful to understanding course grades; $81.2 \%$ found POGIL helpful or very helpful to understanding course content; and 79.2\% found POGIL helpful or very helpful to future teamwork participation. Analysis of the responses for POGIL roles indicated that $23.1 \%$ of respondents found the reflector role helpful or very helpful for future teamwork.

Students in the Medical-Surgical II comparison group were given the opportunity to complete a two-question survey that addressed how helpful completing the case studies were to understand the content taught and to improving grades. Due to the low rate of return this data seemed inconsequential to the study and is not reported.

\subsection{Study limitations}

There are several limitations to the study. Final course grades and end of course standardized national exam test results are the result of numerous variables of learning and teaching strategies, and thus may have influenced the results of this study. Professors who volunteered to utilize the POGIL strategy received limited training, which may have influenced how POGIL was actually used in the classroom and perhaps with better training of professor the results may have been different. Whether the professors used POGIL in a consistent way is not known because an objective observer who could have directly observed classroom use of POGIL was not used. The study was conducted at one private university, on two campuses in an undergraduate baccalaureate-nursing program. Conducting the study at multiple sites in varied locations with different students may have yielded different results.

\section{Discussion}

There was no difference in the final course grades and standardized national exam grades for the Medical Surgical Nursing II POGIL and comparison groups. In the Fundamentals courses, a statistically significant positive difference in standardized national exam scores ( $p=.001$ ) was found in POGIL groups. There was no significant difference in final course grades between the POGIL and comparison groups.

The findings in this study, a significant positive difference in the national standardized exam scores of Fundamentals students, are consistent with findings from a prior pilot study conducted by Roller. ${ }^{[5]}$ The pilot study similarly found a statistically significant positive difference in national stan- 
dardized exam scores $(p=.032)$ when POGIL was used as a pedagogy. In a previous study by Roller and Zori ${ }^{[6]}$ revealed a significant difference in final course grades $(p=$ .046); however, no statistically significant difference was found when standardized exam scores were compared. This inconsistency in improving grades in final course grades and standardized national exam scores with the use of POGIL is similar to findings in studies in disciplines other than nursing. Hein $^{[17]}$ compared students who used POGIL with those who did not in a college chemistry course and found statistically significant positive results in a standardized ACS exam but no difference in final course grades. Chase, Pakhira and Stains ${ }^{[2]}$ found no positive difference in grades when POGIL was used in organic and general chemistry courses. However, despite the inconsistency in findings there does seem to be a trend of improving grades when POGIL is used with students in the Fundamentals courses.

The lack of significant differences in the Medical-Surgical Nursing II nursing students' final course grades and standardized national exam scores is consistent with prior research. $^{[2,5,6,17]}$ It is interesting to note that in the present study, the students were graduating and had taken 4 semesters of clinical nursing courses and thus had likely experienced a variety of both teaching and learning strategies that may have been useful to or influenced their success.

The majority of students in the POGIL groups in both Fundamentals and Medical-Surgical Nursing II courses indicated, through the satisfaction survey, that POGIL was helpful or very helpful to improving their course grade and understanding the material taught. Analyzing case scenarios in a group seems to facilitate student's understanding of the content taught and the application to realistic patient scenarios. Although the improvement in final grades or national standardized test scores was inconsistent in those groups that used POGIL there may be other positive aspects of using POGIL as an active learning strategy that were not captured in this study. Social constructivism theory explains that social interaction and allowing students the opportunity to function in different roles facilitates the development of different perspectives that can lead to deeper learning. ${ }^{[21]}$ It could be that students who are at the beginning stages of a nursing curriculum benefit more from the learning that occurs from the social interaction and assuming different roles in that interaction. Beginning nursing students are learning not only nursing concepts when discussing case studies but through dialogue and social interaction different perspectives are able to be examined and critical thinking applied. The classroom is very animated and thoughtful during a POGIL exercise. This type of interactive discussion may help beginning nursing students practice teamwork, collaboration, and thus the

Published by Sciedu Press assumption of the social norms of the nursing profession.

Senior nursing students may have already internalized the importance of teamwork and collaboration and so did not gain as much benefit from the use of POGIL. Further research that captures the socialization of nurses and development of team work could be very useful in the education of nursing students. Another aspect that was not examined in this study but would be valuable to nursing education and future research was how participating in POGIL in the classroom might influence practice in the clinical setting.

\section{Implications and recommendations}

The impact of POGIL as an interactive learning strategy on final grades and national standardized tests has been studied in beginning nursing student's Fundamentals classes and graduating student's Medical Surgical Nursing classes with varying results. These results are consistent with prior POGIL research both in nursing and in other fields of science. Replicating the current study in other nursing courses such as mental health or care of the evolving family at varying points in the curriculum could provide interesting comparisons and analysis of the impact of POGIL $n$ course grades and standardized tests as students move through the curriculum and progress towards graduation.

However, another avenue of inquiry to consider in nursing education research is the impact that POGIL may have on the development of teamwork, collaboration and adoption of social norms especially in beginning nursing students.

Research that could also potentially show linkages between use of POGIL in theory class and how it might relate to the development of clinical thinking in practice settings would also be very interesting as we strive to educate nurses to shape health care for the future.

\section{Conclusions}

Using POGIL in Fundamentals courses showed improvement in national standardized test scores but not course grades. Using POGIL in Medical-surgical nursing II courses did not reveal significant differences in national standardized exam scores or final course grades. Students who engaged in POGIL in the classroom had better understanding of course content and grades. A priority in nursing education is to enhance the development of clinical thinking and teamwork and using POGIL in undergraduate nursing courses may be one strategy that helps to achieve these goals. Additional research on the use of the POGIL method in nursing education is warranted.

\section{CONFlicts OF INTEREST Disclosure}

The authors declare that there is no conflict of interest. 


\section{REFERENCES}

[1] Burrell LA. Integrating critical thinking strategies into nursing curricula. Teaching and Learning in Nursing. 2014; 9 (2): 53-58 https://doi.org/10.1016/j.teln.2013.12.005

[2] Chase A, Pakhira D, Stains M. Implementing process-oriented guided-inquiry learning for the first time: adaptations and short-term impacts on students' attitude and performance. Journal of Chemical Education. 2013; 90: 409-416. https : //doi.org/10.1021/ed30 $0181 t$

[3] De Gale S, Boisselle L. The Effect of POGIL on Academic Performance and Academic Confidence. Science Education International. 2015; 26(1): 56-79.

[4] Murray TA. Teaching students to read the primary literature using POGIL activities. Biochem. Mol. Biol. Educ. 2014; 42(2): 165-173. PMid:24376102 https ://doi .org/10.1002/bmb. 20765

[5] Roller MC. Fundamental Nursing: Process-Oriented Guided-Inquiry Learning (POGIL) Research. Journal for Leadership and Instruction 2015; 14(1): 20-23.

[6] Roller MC, Zori S. The impact of instituting Process-Oriented Guided-Inquiry Learning (POGIL) in a fundamental nursing course. Nurse Education Today. 2017; 50: 72-76. PMid:28012981 https: //doi.org/10.1016/j.nedt.2016.12.003

[7] Simonson SR, Shadle SE. Implementing Process-Oriented GuidedInquiry Learning (POGIL) in undergraduate biomechanics.

[8] Moog RS. Process Oriented Guided Inquiry Learning. In MA McDaniel, RF Frey, SM Fitzpatrick, HL Roediger (Eds.), Integrating cognitive science with innovative teaching in STEM disciplines. St. Louis: Washington University in St. Louis Libraries. 2014. [Ereader version]

[9] POGIL. Description of roles POGIL: Process Inquiry Guided Inquiry Learning. 2016. Available from: http://www.pogil.org/uploads/media_items/descri ptions-of-rolesexpanded.original.pdf (n.d.).

[10] O'Flaherty J, Phillips C. The use of flipped classrooms in higher education: A scoping review. Internet and Higher Education. 2015; 25: 85-95. https://doi.org/10.1016/j.iheduc.2015.02.002

[11] Njie-Carr et al. An integrative review of flipped classroom teaching models in nursing education. Professional Nursing. 2017; 33: 133 -
144. PMid:28363388 https://doi.org/10.1016/j.profnurs .2016 .07 .001

[12] Chan Z. A systematic review of critical thinking in nursing education. Nurse Education Today. 2013; 33: 236-240. PMid:23394977 https://doi.org/10.1016/j.nedt.2013.01.007

[13] Martyn J, Terwijn R, Kek M, et al. Exploring the relationships between teaching, approaches to learning and critical thinking in a problem-based learning foundation course. Nurse Education Today. 2014; 34: 829-835. PMid:23706962 https ://doi.org/10.1016/ j.nedt . 2013.04 .023

[14] Zori S. Teaching critical thinking using reflective journaling in a nursing fellowship program. Journal of Continuing Education in Nursing. 2016; 47(7): 321-329. PMid:27351265 https ://doi.org/10.3 928/00220124-20160616-09

[15] Mulligan EA. Use of a modified POGIL exercise to teach bacterial transformation in a microbiology course. Journal of Microbiology \& Biology Education. 2014; 30-32.

[16] Soltis R, Verlinden N, Kruger N, et al. Process-oriented guided inquiry learning strategy enhances students' higher level thinking skills in a pharmaceutical sciences course. American Journal of Pharmacy Education. 2015; 79(1): 1-8.

[17] Hein SM. Positive impacts using POGIL in organic chemistry. Journal of Chemical Education. 2012; 89: 860-864. https://doi.or g/10.1021/ed100217v

[18] Maurer TW. Teaching financial literacy with processoriented guided-inquiry learning (POGIL). Journal of Financial Education. 2015; 40(3): 140-163. Available from: https : //search-proquest-com.libproxy.adelphi.edu : $2443 /$ docview/1640901529? accountid=8204

[19] Piaget J. The construction of reality in the child. Abingdon, Oxdon: Routledge \& Kegan, Paul. 1954. Available from: https: //books.google.com/books?id=mVROynAYcI8C

[20] Vygotsky LS. Mind in society: The development of higher psychological processes. Boston: Harvard University Press; 1980.

[21] Walker CL, Shore BM. Understanding classroom roles in inquiry education: Linking role theory and social constructivism to the concept of role diversification. 2015; 1-13. 